\title{
Generality of the failure-to-escape (helplessness) phenomenon in rats
}

\author{
JON S. FREDA and STEPHEN B. KLEIN \\ Old Dominion University, Norfolk, Virginia 23508
}

\begin{abstract}
A series of four experiments investigated a number of parameters reported to produce "helplessness" in rats. Consistent differences in escape behavior were not found between inescapably shocked and restrained rats when a FR 1 shuttling response was used. Escape latencies also did not differ between groups when a reduced shock intensity was employed during escape training in FR 2 procedure or when an increased FR 3 response was employed during escape training. Findings are discussed in terms of the robustness of the failure-to-escape phenomenon from which "helplessness" in the rat is inferred.
\end{abstract}

Recent observations have shown that dogs exposed to unsignaled inescapable shocks in a restraining hammock subsequently failed to learn to escape signaled shocks in a shuttlebox, whereas dogs exposed to unsignaled escapable shocks successfully learned to escape signaled shocks in the novel shuttlebox (Overmier, 1968; Overmier \& Seligman, 1967; Seligman \& Maier, 1967). With the triadic design, one group of dogs receives as its pretreatment an outcome it can control; a second group, yoked to the first, receives outcomes identical to the first except that there is no response that can modify these outcomes; and a third group receives no pretreatment. It has been suggested that following inescapable shock, the dogs in the yoked condition learned that the occurrence of shock is response-independent. The expectancy that outcomes are independent of behavior accounts for "helplessness," rather than the experience of shock per se (Maier, 1970; Seligman, 1975; Seligman \& Maier, 1967).

In an attempt to provide generality of findings, Maier, Albin, and Testa (1973) conducted a series of experiments to find a procedure which would reliably produce failure to escape in the rat. Specifically, by manipulating the intensity of shock, the number of shocks, and the intershock interval, they attempted to identify a set of inescapable shock parameters which would result in subsequent failure to escape in an escape-avoidance test situation. They found that rats were not helpless when escape responding involved a one-way shuttle (FR 1) response similar to that which produced helplessness in the dog, but that requiring two shuttle responses (FR 2) for escape made about half the rats helpless.

The observation that rats exposed to inescapable

Requests for reprints should be sent to Dr. Stephen B. Klein, Psychology Department, Old Dominion University, Norfolk, Virginia 23508. shock under a wide range of parameters do not exhibit an interference effect when only a one-way escape response is required has led some investigators (Maier et al., 1973; Anderson et al., Note 1) to consider the possibility that dogs and rats learn differently to escape in a shuttlebox, and that they may otherwise be equally susceptible to the interfering effects of prior exposure to inescapable shocks. The suggestion has been that, regardless of shock intensity, number of shocks, and the intershock interval during pretreatment, rats respond more reflexively during the one-way shuttle test. While dogs exhibit longer latencies of response initiation on the first trial and shorter escape latencies on later trials (Seligman \& Maier, 1967), the escape latencies of rats are as short on the first trial as on later ones.

Further investigations by Maier and Testa (1975) have shown that inescapably shocked rats fail to learn to escape shock in a shuttlebox when FR 2 shuttling is required for shock termination, but learn the FR 2 response when a brief interruption of shock occurred after the first of the two shuttles. They interpret their results as demonstrating that the effect of prior exposure to inescapable shock on subsequent acquisition of an escape response in rats is determined by the nature of the contingency between shuttling and shock termination, and not by the amount of physical effort required to initiate and maintain the escape response, nor by the amount of shock that is administered during an escape trial.

Given the importance of the phenomenon and interpretation with which Maier et al. are working, it seems important to report failures to replicate the basic helplessness phenomenon using very close approximations of Maier's procedures. We report four experiments in which the only major departure from Maier's procedure was that the rats were placed in a holding cage during the intertrial interval. 


\section{EXPERIMENT I}

Experiment I was an attempt to produce helplessness using procedures similar to those of Maier et al. (1973). One group of rats was exposed to inescapable shocks and a second group of rats was restrained but not shocked. Twenty-four hours later, all groups received escape-avoidance training in a two-way shuttlebox as described in detail later.

\section{Method \\ Subjects. The subjects were 16 male Charles-River rats of the Sprague-Dawley strain and were 90-120 days old at time of testing. All rats were individually housed with food and water ad lib. In all experiments, the rats were maintained in the laboratory for a minimum of 1 week before the start of the experiment. The rats were handled daily the last few days prior to the beginning of experimentation.}

Apparatus. The restraining device in which inescapable shock (IS) was delivered was a Plexiglas rectangular box with wood floor, $16 \mathrm{~cm}$ in length, $7 \mathrm{~cm}$ in width, and $9 \mathrm{~cm}$ in height. After the rat was placed in the box, its tail was pulled through a hole at the end of the box and secured with adhesive tape to prevent the rat from pulling the tail through during IS delivery. Direct shock was delivered from a Grason-Stadler Model 700 shock generator through electrodes taped to the rat's tail and augmented with electrode paste. Prior to attachment of electrodes, hair cream remover was applied to the rat's tail to reduce electrical resistance provided from the hair on the tail.

Escape-avoidance training (ET) was conducted in a standard two-way shuttlebox manufactured by Lafayette Instrument Co. The shuttlebox was $62 \mathrm{~cm}$ in length, $21 \mathrm{~cm}$ in width, and $19 \mathrm{~cm}$ in height. The center of the shuttlebox contained a metal divider with a rectangular opening, $7.5 \mathrm{~cm}$ high and $5.8 \mathrm{~cm}$ wide. Therefore, to complete a shuttle response from one chamber to the other, the rat was required to run completely through the opening. Scrambled shock was delivered from a Grason-Stadler Model 700 shock generator through floor grid bars in the shuttlebox.

Procedure. The rats were randomly divided into two groups of eight subjects each-an inescapably shocked (IS) group and a restrained $(R)$ only group. The IS group received 645.0 -sec 1.0 -mA shocks while in the restraining box. The interval between shocks was a mean of $60 \mathrm{sec}$ with a range of 5-115 sec. Three restraining boxes were aligned next to each other so that three rats could be administered IS simultaneously. The electrodes were placed in series to ensure equitable temporal and amperage IS deliveries, which were automatically delivered by means of a ribbon timer. The total time of confinement in the chamber was approximately $70 \mathrm{~min}$. The $\mathbf{R}$ group was placed in the restraining box with electrodes attached to their tails for $70 \mathrm{~min}$ but not shocked.

Twenty-four hours after IS and $\mathrm{R}$ treatments, all rats received 30 trials of ET in the shuttlebox. Prior to the first trial, each rat was placed in the shuttlebox for a 5-min adaptation period without the presentation of the CS and US. At the end of the adaptation period, the rat was removed from the shuttlebox and placed in its holding cage. After a duration equal to the first intertrial interval (ITI), the animals were placed in the shuttlebox and the first acquisition trial was given. The first five trials required a FR 1 criterion of one crossing through the opening to escape shock. The subsequent 25 trials required a FR 2 criterion of two crossings. The onset of a CS (white light illuminating both chambers simultaneously and the presence of a sona-alert tone) began each trial, and remained on until trial termination. The CS-US interval was $5.0 \mathrm{sec}$. During the FR 1 trials, if a rat crossed the shuttlebox once during this interval, the CS was terminated and no shock occurred. Failure to cross during this interval produced a $1.0-\mathrm{mA}$ shock (US) to one chamber in which the rat was located, and remained on until the rat ran through the opening. If the rat failed to cross the shuttlebox to the other chamber within $30 \mathrm{sec}$ after US onset, the trial was terminated and a 35 -sec total latency was recorded. There was a mean 60 -sec intertrial interval (ITI) with a range of 5-115 sec. During each ITI, the rat was placed in its holding cage. For the next 25 trials, a FR 2 criterion of two crossings was required for CS-US termination. The CS-US interval, ITI, and maximum duration of US after onset were the same as those for FR 1. However, shock onset during FR 2 trials produced scrambled shock simultaneously to both thambers of the shuttlebox. Shock termination resulted when the rat's front and hind paws were fully located in the chamber after the second crossing.

\section{Results and Discussion}

Figure 1 shows mean latency from CS onset to completion of the escape avoidance response for IS and R groups across FR 1 and FR 2 trial blocks. As in prior experiments (Maier et al., 1973), there was no difference in escape behavior between groups when only one crossing (first five trials) was required. However, no difference was found in FR 2 escape performance between IS and $\mathrm{R}$ groups.

Statistical analysis confirms these findings. A one-way analysis of variance showed that escape latencies during FR 1 trials were equivalent for IS and $R$ groups $(F=0.15$, df $=1 / 14, p>.05)$. A 2 by 5 repeated-measures analysis of variance of FR 2 performance indicated a nonsignificant Treatment effect $(F=0.47$, df $=1 / 14, p>.05)$, a significant Blocks effect $(F=9.38, \mathrm{df}=4 / 56$, $\mathrm{p}<.05$ ), and a nonsignificant Treatment by Blocks interaction $(F=0.56, \mathrm{df}=4.56, \mathrm{p}>.05)$. Subsequent Tukey (hsd) post hoc comparisons $(p<.05)$ showed that, for both groups combined, shuttle performance on the first block of FR 2 trials was faster than the other blocks.

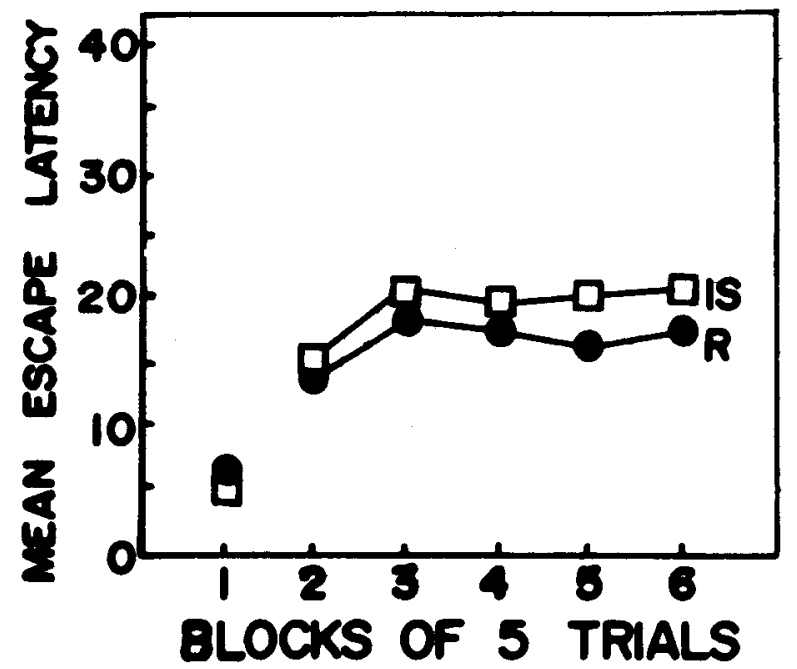

Figure 1. Mean latency in seconds from $C S$ onset to the completion of the escape-avoidance response for IS and $\mathbf{R}$ groups across blocks of five trials. (The escape response is FR 1 shuttling on the first block and FR 2 on subsequent blocks.) (Experiment I) 
These results are at variance with those previously reported by Maier et al. (1973). From these findings, it seemed necessary that a second attempt at producing "helplessness" be made, investigating whether or not response-debilitation could be observed between IS and $R$ groups on escapeavoidance performance.

\section{EXPERIMENT II}

\section{Method}

Subjects. The subjects were 16 male Charles-River rats of the Sprague-Dawley strain, 90-120 days old at time of testing. Housing requirements and sustenance access were the same as in Experiment 1.

Apparatus. The apparatus was identical to that used in Experiment I.

Procedure. The procedure was the same as in Experiment I.

\section{Results and Discussion}

Mean latency from CS onset to completion of the escape-avoidance response for IS and $\mathbf{R}$ groups across FR 1 and FR 2 trial blocks is shown in Figure 2. As in Experiment I, no difference in FR 1 performance was found between IS and $\mathrm{R}$ rats. Unlike the results in Experiment I, exposure to inescapable shock did produce failure to escape during FR 2 acquisition during Block 4. However, the increase in response latency was not as great between treatment blocks as that reported by Maier et al. and was not present in Blocks 2 and 3 and Blocks 5 and 6.

Statistical analysis of FR 1 performance showed equivalent escape latencies during the FR 1 session in $I S$ and $R$ rats $(F=1.24$, df $=1 / 14, p>.05)$. A 2 by 5 repeated-measure analysis of variance of FR 2 performance demonstrated a significant Treat-

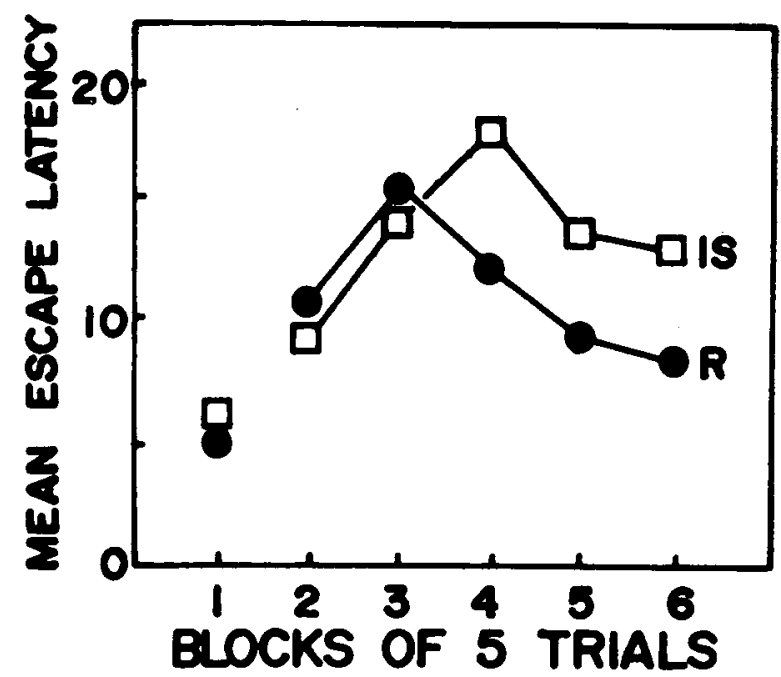

Figure 2. Mean latency in seconds from CS onset to the completion of the escape-avoidance response for IS and $R$ groups across blocks of five trials. (The escape response is FR 1 shuttling on the first block and FR 2 on subsequent blocks.) (Experiment II) ment effect $(F=10.73, \mathrm{df}=1 / 14, \mathrm{p}<.05)$, Blocks effect $(F=14.29$, df $=4 / 56, \quad p<.05)$, and Treatment by Blocks interaction $(F=11.05$, $\mathrm{df}=4 / 56, \quad \mathrm{p}<.05$ ). Subsequent Tukey (hsd) post hoc comparisons $(p<.05)$ between mean latencies involved in the interaction indicated that the shuttle performance of IS rats became slower during the middle block of FR 2 trials, but did not appreciably differ from that of the $R$ group during the early and later blocks of FR 2 acquisition. These findings are in direct contrast to those obtained in Experiment I. Yet, even in this study, inescapable shock only produced a small and transient disruption of escape performance. In no case did performance approximate failure to escape as is found in the dog studies.

Maier (Note 2) has presented an alternative possibility which may account for these inconsistent findings. After having completed his series of studies concerned with constructing a set of IS parameters for producing "learned helplessness" in rats, Maier found that the actual ET shock parameters were discrepant with those described in earlier papers. That is, although source amperage indicated $1.0 \mathrm{~mA}$ to the grid bars of the shuttlebox during ET, actual delivered amperage was $0.6 \mathrm{~mA}$. The drop in amperage was related to the long length of the connector cord between the shock generator and shuttlebox. Maier (Note 2) reports that he was unable to produce IS interference when the actual ET shock level was $1.0 \mathrm{~mA}$ but was able to when the level was .6 mA. With respect to the inconsistent findings obtained in the present two experiments, it is suggested that as the intensity of aversive stimulation approaches equivalence for both the IS and ET situations, the probability of obtaining response differences between IS and $R$ rats decreases. In addition, it has been reported that with use of the original parameters for producing failure to escape in the rat, only half of the IS rats displayed escape latencies significantly different from those of the $R$ rats in the shuttlebox situation (Maier \& Testa, 1975). Therefore, in order to increase the probability of obtaining performance differences between IS and $R$ rats, a third experiment was conducted to examine the effects of reduced ET amperage on failure to escape in the rat.

\section{EXPERIMENT III}

Experiment III asked whether IS rats would show an interference effect in an escape-avoidance situation which presented contingent shock of an intensity lower than that used to administer IS in pretreatment.

\footnotetext{
Method

Subjects. The subjects were 16 male Charles-River rats of the Sprague-Dawley strain, 90-120 days old at time of testing. Housing
} 
requirements and sustenance access were the same as in Experiments I and II.

Apparatus. The apparatus was identical to that used in Experiments I and II.

Procedure. The procedure was similar to that employed in Experiments I and II, except that during ET, shock was delivered at $0.6 \mathrm{~mA}$ to the grid bars of the shuttlebox.

\section{Results and Discussion}

Figure 3 shows mean latency from CS onset to completion of the escape-avoidance response for IS and R groups across FR 1 and FR 2 trial blocks. As in the previous experiments, IS and $R$ rats exhibited no difference in escape behavior during FR 1 responding. In addition, no difference in FR 2 performance was found between IS and R groups.

Statistical analysis of FR 1 performance between IS and $\mathbf{R}$ groups revealed a nonsignificant Treatment effect $(F=.99$, df $=1 / 14, p>.05)$. A 2 by 5 repeated-measures analysis of variance on five FR 2 trials showed nonsignificant Treatment effects $(F=2.70, \mathrm{df}=4 / 56, p>.05)$, Blocks effect $(\mathrm{F}=2.70$, df $=4.56, \mathrm{p}>.05)$, and Treatment by Blocks interaction $(F=.90$, df $=4 / 56, p>.05)$. IS rats did not fail to escape when the intensity of shock was lowered during the escape-avoidance situation. These findings do not support Maier's contention that helplessness would be produced utilizing a lower shock level $(.6 \mathrm{~mA})$ during ET than was employed during IS experience (1.0 mA).

Maier (Note 2) suggested that an increase in the complexity of the performance task (to FR 3 ) would also enhance the probability of obtaining the response-debilitation effect in IS rats. To investigate this possibility, a fourth experiment was conducted in which a FR 3 (three crossings required to terminate

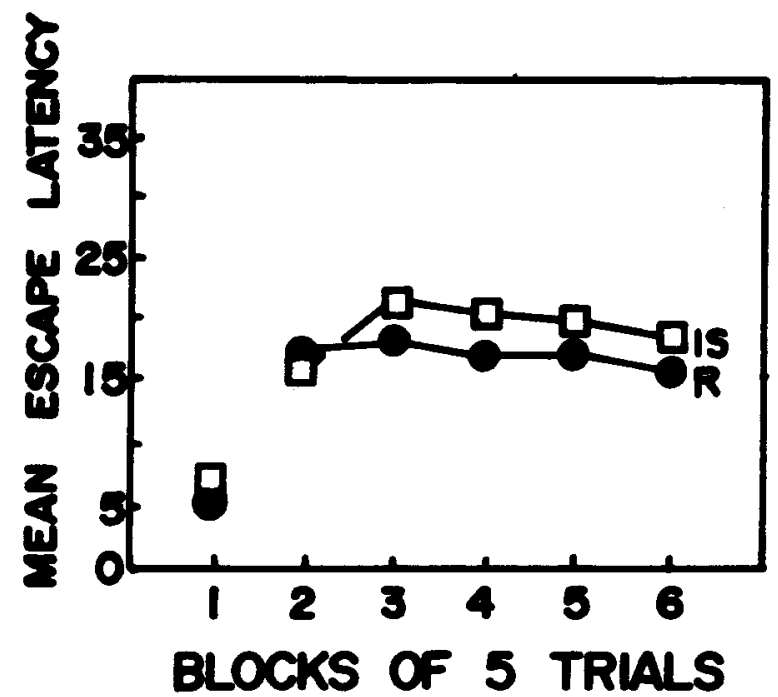

Figure 3. Mean latency in seconds from CS onset to the completion of the escape-avoidance response for IS and $R$ groups across blocks of five trials. (The escape response is FR 1 shuttling on the first block and FR 2 on subsequent blocks.) (Experiment III) shock) response replaced the FR 2 requirement used in the previous experiments.

\section{EXPERIMENT IV}

The purpose of the fourth experiment was to determine if a complex task of three crossings to terminate shock would inhibit the reflexive nature of escape responding in inescapably shocked rats found in the previous three experiments and produce "helplessness" in the shuttlebox.

\section{Method}

Subjects. The subjects were 16 male Charles-River rats of the Sprague-Dawley strain, 90-120 days old at time of testing. Housing requirements and sustenance access were the same as in Experiments I, II, and III.

Apparatus. The apparatus was identical to that used in Experiments I, II and III.

Procedure. The procedure was similar to that employed in Experiments I and II except that during ET, the S FR 1 trials were followed by 25 trials requiring FR 3 acquisition.

\section{Results and Discussion}

Mean latency from CS onset to completion of the escape-avoidance response for IS and $R$ groups across FR 1 and FR 3 trial blocks is shown in Figure 4. As in Experiments I, II, and III, escape behavior did not differ between IS and $R$ rats during FR 1 performance. No difference in escape latency was observed between IS and R groups during FR 3 acquisition either.

An analysis of FR 1 performance revealed no differences in escape behavior between IS and $R$ rats $(F=.11, \mathrm{df}=1 / 14, \mathrm{p}>.05)$. A 2 by 5 repeatedmeasures analysis of variance of FR 3 acquisition showed a nonsignificant Treatment effect $(F=.14$, $\mathrm{df}=1 / 14, \mathrm{p}>.05$ ), a significant Blocks effect $(F=8.59, \mathrm{df}=4 / 56, p<.05)$, and a nonsignificant Treatment by Blocks interaction $(F=1.06$, df $=4 / 56, \quad p>.05$ ). Subsequent Tukey (hsd) post hoc comparisons $(p<.05)$ showed that, for both groups combined, shuttle performance on the first and second blocks of FR 3 trials was faster than that during the fourth and fifth blocks of FR 3 acquisition.

An increase in the complexity of the performance task did not result in significant differences of escape behavior between the IS and $R$ groups. It is interesting to note, however, that the overall latencies of both groups approached that previously reported only for inescapably shocked animals (Maier et al., 1973; Maier \& Testa, 1975). It seems that in such a highly complex situation, the flight reaction in rats precluded the acquisition of the FR 3 response. Repeated observations made of the rats' behavior during FR 3 acquisition confirm this notion. That is, the majority of rats from both groups attempted to escape from the shuttlebox 


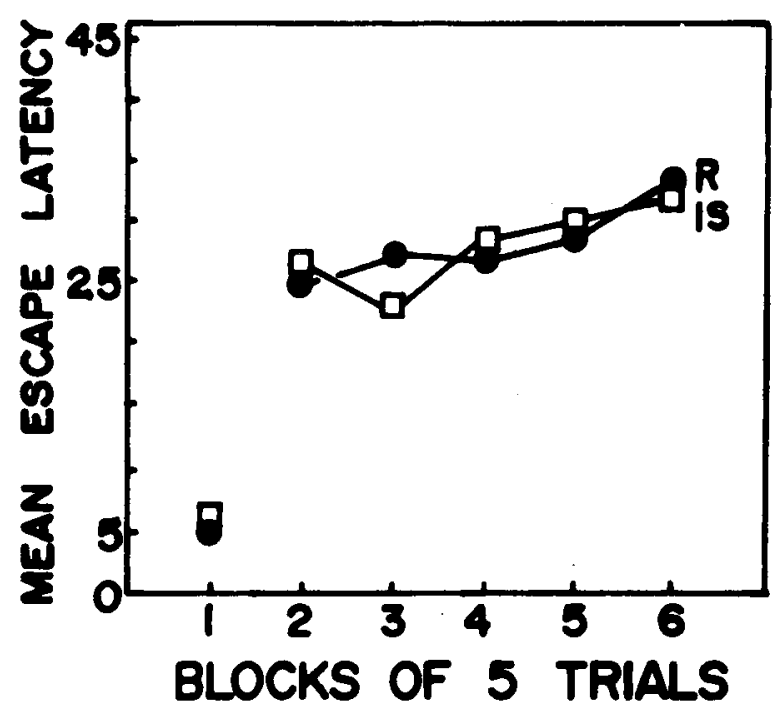

Figure 4. Mean latency in seconds from $\mathrm{CS}$ onset to the completion of the escape-avoidance response for IS and $\mathbf{R}$ groups across blocks of five trials. (The escape response is FR 1 shuttling on the first block and FR 3 on subsequent blocks.) (Experiment IV)

after making the first or second crossing. In no case did any of the rats sit passively, taking the shock, nor did any of them exhibit back-rolling. It is suggested that the the manipulation of a reflexive response, as manifested in the escape behavior of the rat, may at best result in differential outcomes dependent upon rigidly controlled parameters, rather than on a perceived expectancy of response-independence.

\section{GENERAL DISCUSSION}

Results observed in the second experiment showed slower escape latencies after pretreatment with a set of IS parameters similar to those used by Maier to produce "helplessness" in rats, but this effect was small and transient. No differences between IS and $R$ rats were observed in Experiment $I$, even though the procedures were identical to those in Experiment II. Additionally, there were no effects of IS exposure in Experiments III and IV. These two experiments failed to provide support for the methods which Maier (Note 2 ) reports produce "helplessness" in the rat.

There is one procedural difference between Maier's and our studies. In Maier's research, subjects were left in the apparatus during the ITI, whereas the rats were removed and placed in a holding cage during the ITI in our experiments. Although handling during the ITI has been reported to improve FR 1 shuttling in rats (Wahlsten \& Sharp, 1969), it seems unlikely that handling resulted in an absence of "helplessness" using FR 2 and FR 3 shuttling in the present studies. If handling were to decrease escape latencies in complex situations, and the effect in IS and R groups was the same, this would not eliminate the interference effect. It is possible that handling interacted with treatment condition, thereby preventing IS interference in the present experiments. However, if such a procedural difference affected failure-to-escape behavior in the rat, then the generality of interpretation in terms of helplessness would not be very great.

The failure to escape (interference) phenomenon has been produced in the rat using other experimental procedures. Seligman and his associates (Seligman \& Beagley, 1975; Seligman, Rosellini, \& Kozak, 1975) report that rats show "helplessness" in barpress situations, while Looney and Cohen (1972) observed "helplessness" in a jump-up escape response. Our results do not, of course, reflect on these other procedures for producing interference effects following inescapable shock.

It is not the purpose of this article to evaluate whether learned helplessness is a reasonable explanation for the interference effect from inescapable shock in rats or humans (see Maier \& Seligman, 1976, for complete discussion of the helplessness literature). Yet, failures to replicate the basic effect under slightly different conditions in different laboratories is disturbing given the degree to which the "helplessness" findings have been generalized. If minor procedural variations prevent IS interference, then the cognitive theory proposed by Seligman and Maier would seem to lose explanatory power. Minor procedural variations should not affect an organism that is learning it has no control over its environment. If, as previously reported by Maier and Seligman (1976), the associative interference produced by inescapable shock can transfer across situations and generalize across species, why should feedback or handling have such a profound effect?

\section{REFERENCE NOTES}

1. Anderson, D. C., Schwendiman, G., \& Payne, R. Prior unsignaled, inescapable shock trauma in the rat. Paper presented at the meeting of the Western Psychological Association, San Diego, March 1968.

2. Maier, S. F. How to get helplessness in rats. Paper presented at the meeting of the Psychonomic Society, Denver, October 1975.

\section{REFERENCES}

Looney, T. A., \& Cohen, P. S. Retardation of jump-up escape responding in rats pretreated with different frequencies of noncontingent electric shock. Journal of Comparative and Physiological Psychology, 1972, 78, 317-322.

MAIER, S. F. Failure to escape traumatic shock: Incompatible skeletal-motor responses or learned helplessness? Learning and Motivation, 1970, 1, 157-169.

Maier, S. F., Albin, R. W., \& Testa, T. Failure to learn to escape in rats previously exposed to inescapable shock depends on nature of escape response. Journal of Comparative and Physiological Psychology, 1973, 85, 581-592.

Maier, S. F., \& Seligman, M. E. Learned helplessness: Theory and evidence. Journal of Experimental Psychology: General. 1976, 105, 3-46. 
Maier, S. F., \& Testa, T. Failure to learn to escape by rats previously exposed to inescapable shock is partly produced by associative interference. Journal of Comparative and Physiological Psychology, 1975, 88, 554-564.

OVERMIER, J. B. Interference with avoidance behavior: Failure to avoid traumatic shock. Joumal of Experimental Psychology, $1968,78,340-343$.

Overmier, J. B., \& Seligman, M. E. Effects of inescapable shock upon subsequent escape and avoid ance responding. Journal of Comparative and Physiological Psychology, 1967, 63, 28-33.

Seligman, M. E. Helplessness. San Francisco: Freeman, 1975.

Seligman, M. E., \& Beagley, G. Learned helplessness in the rat. Journal of Comparative and Physiological Psychology, 1975, 88, 534-541.
Seligman, M. E., \& Marer, S. F. Failure to escape traumatic shock. Joumal of Experimental Psychology, 1967, 74, 1-9.

Seligman, M. E., Rosellini, R. A., \& Kozak, M. Learned helplessness in the rat: Reversibility, time course, and immunization. Journal of Comparative and Physiological Psychology, $1975,88,542-547$.

W AFLSTEN, D., \& ShARP, D. Improvement of shuttle avoidance by handling during the intertrial interval. Journal of Comparative and Physiological Psychology, 1969, 67, 252-259.

(Received for publication February 23, 1976; revision received June $15,1976$. ) 